Alma Mater Studiorum - Università di Bologna DEPARTMENT OF ECONOMICS

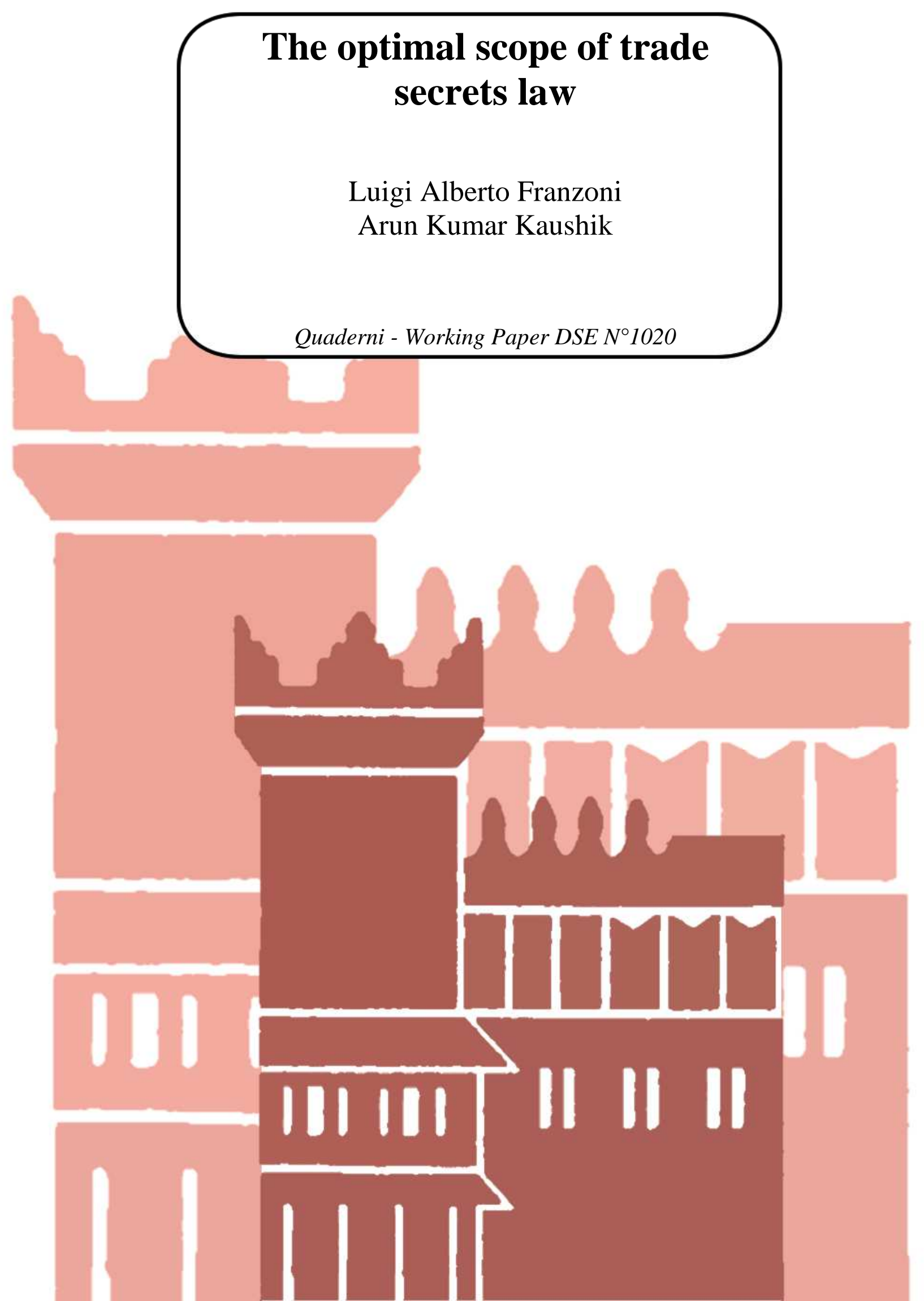




\title{
The optimal scope of trade secrets law
}

\author{
Luigi Alberto Franzoni* $\quad$ Arun Kumar Kaushik ${ }^{\dagger \ddagger}$
}

July 2015

\begin{abstract}
The paper investigates the optimal scope of trade secrets law. In the model, one innovative firm invests resources first to produce knowledge, and then to protect it from unwanted disclosure. A rival firm invests to ferret out this knowledge. Trade secrets law affects this "secrecy contest" by reducing the probability of unwanted disclosure given the efforts of the parties. We show how optimal trade secrets policy depends on structural market features and cost parameters. In the final section, we consider the limit case in which the innovation lies on the face of the product, and derive the optimal scope of legal provisions preventing copycat imitation of products (unfair competition, passing off).
\end{abstract}

Keywords: trade secrets law, unfair competition, parasitic competition, slavish imitation, passing off.

JEL codes: K1, L1.

\footnotetext{
${ }^{*}$ Corresponding Authour. Department of Economics, University of Bologna, Piazza Scaravilli 2, 40126 Bologna, Italy.

${ }^{\dagger}$ O.P. Jindal Global University, India.

${ }^{\ddagger}$ We thank the editor Scott Baker and an anonymous referee for their constructive remarks. We are also grateful to Vincenzo Denicolò, Valeria Falce, Marco Ricolfi, Hans-Bernd Schaefer, Louis Visscher, and seminar participants in Lugano, Paris X, Lima (ALACDE), Aix en Provence (EALE), and Rome (SIDE) for helpful comments.
} 


\section{Introduction}

In modern economies, the competitive advantage that firms enjoy on the market depends increasingly on their specific expertise and knowledge, rather than on manufacturing costs differentials. To protect this knowledge, firms can rely on different legal tools, including patents (for non-obvious inventions) and copyright (for novel pieces of creative work). Yet, most companies tend to rely on the oldest, and most likely the cheapest, form of protection: secrecy. ${ }^{1}$

The desire of companies to keep their competitive knowledge secret is not discouraged by the law. To the contrary, the law supports the secret conservation of knowledge, by sanctioning conducts aimed at the violation of confidential business information, such as unauthorized disclosure and espionage. In this respect, however, the law is called upon to strike a difficult balance between the right of the knowledge holder to preserve secrecy and the need of society to promote the dissemination of valuable information. In fact, the diffusion of innovative knowledge encourages imitation and fosters competition in the market. Excessive secrecy protection, by retarding the dissemination of the information in the economy, might not serve the interests of consumers well. ${ }^{2}$

In this paper, we investigate the optimal scope of trade secrets (TS) law and highlight the basic trade-offs that policy it called upon to address. In particular, we develop a simple model in which a firm can create innovative knowledge that provides a head-start advantage in the market. Once the knowledge is created, a rival firm invests resources to ferret out this knowledge, whereas the innovator invests resources to protect it. TS law affects this secrecy contest by reducing the probability of knowledge leakage, given the efforts of the parties. So, TS law affects the investments of the parties in the secrecy contest and the final market structure.

Before illustrating the model, it is important to clarify the multifaceted nature of TS law. As opposed to patent law, which shares the same basic features in most jurisdictions, TS law varies substantially across countries. In most jurisdictions, provisions regulating the protection of confidential know-how are scattered in several

\footnotetext{
${ }^{1}$ Recent empirical work by Hall et al. (2013) shows that in the UK only $4 \%$ of innovating companies patent. In the US, approximately $5.5 \%$ of all manufacturing firms engage in patenting activity (Balasubramanian and Sivadasan 2011). Arundel (2001) finds that European manufacturers investing in R\&D rate secrecy as more important than patents for the protection of their innovations.

${ }^{2}$ As aptly remarked by the US Supreme Court in In Bonito Boats v. Thunder Craft Boats 489 U.S. 141 (1989) : "[...] imitation and refinement through imitation are both necessary to invention itself, and the very lifeblood of a competitive economy." In this case, the US Supreme Court invalidated a Florida statute prohibiting plug moulding of vessel designs.
} 
bodies of the law, including tort law, contract law, employment law, criminal law, and - occasionally - intellectual property (IP) law. The country that has made the greatest effort to provide a unified framework for TS protection is most likely the US, where the Uniform Trade Secrets Act (UTSA) of 1979, amended 1985, has been adopted by most states.

Provisions close to those of the UTSA have been included in the international Trade-Related Aspects of Intellectual Property Rights (TRIPs) agreement of 1994, which requires WTO member countries to provide legal protection to undisclosed information (art. 39, see below). In spite of the TRIPs agreement, significant variations with respect to substantial TS law persist across the world and across EU countries (Backer-McKenzie 2013, Lippoldt and Schultz 2014). ${ }^{3}$ This has prompted an initiative of the European Commission aimed at imposing uniform legislation across the Union (Proposal 2013/0402). The proposed directive provides for a common definition of protectable knowledge and stipulates the remedies available in case of misappropriation. ${ }^{4}$

To frame our analysis, we will follow the definition of TS provided by the TRIPs agreement, which stipulates that (Art 39.2):

Natural and legal persons shall have the possibility of preventing information lawfully within their control from being disclosed to, acquired by, or used by others without their consent in a manner contrary to honest commercial practices so long as such information: (a) is secret [...]; (b) has commercial value because it is secret; and (c) has been subject to reasonable steps under the circumstances, by the person lawfully in control of the information, to keep it secret.

From this definition, we learn that publicly available information and everyday knowledge are not eligible for legal protection; valueless information and information not subject to reasonable protection do not qualify as trade secrets.

Remedies for misappropriation usually include injunctive relief and damage awards.

Compared with patents and other types of intellectual property, trade secrecy is characterized by several distinguishing features.

First, it does not require any form of registration. This does not mean, however, that it can be protected at no cost. In fact, TS protection can be extremely expensive,

\footnotetext{
${ }^{3}$ Undisclosed business information is protected under the common law of confidentiality in England, whereas it is protected under unfair competition law (Unlauterer Wettbewerb) in Germany. In France, the protection of manufacturing secrets is regulated by the Code of Intellectual Property. See Backer-McKenzie (2013).

${ }^{4} \mathrm{~A}$ plan to strengthen TS protection in the US has been put forward by the Obama administration at about the same time (see Executive Office, 2013).
} 
depending on the type of information concerned. Expenses usually relate to the installation of safety devices, the organisational efforts to avoid the leakage of the information, and the costs related to the imposition of confidentiality restrictions in contractual relationships.

Second, the subject matter is extremely broad, as it encompasses any type of undisclosed information able to provide a competitive advantage to its owner. ${ }^{5}$

Finally, the law does not provide an "exclusive right" to the holder of the secret. Rather, the law draws the line between the sets of the lawful and unlawful ways in which information can be obtained and used. For civil remedies to be applicable, the secret must have been acquired in "a manner contrary to honest commercial practices," which means, under the TRIPs agreement: "at least practices such as breach of contract, breach of confidence and inducement to breach, and includes the acquisition of undisclosed information by third parties who knew, or were grossly negligent in failing to know, that such practices were involved in the acquisition." (art. 39, footnote 10). Under the UTSA, improper means of acquisition of a secret include: "theft, bribery, misrepresentation, breach or inducement of a breach of a duty to maintain secrecy, or espionage through electronic or other means." Conversely, independent creation, discovery through reverse engineering, and acquisition from public sources represent traditional forms of legitimate appropriation of the secret. ${ }^{6}$ By drawing the line between the lawful and unlawful ways in which information can be acquired, the law defines the scope of TS law.

The following examples illustrate the point. Let us consider the case of an employee who leaves her company to work for a competitor. Should the employee be allowed to take with her the knowledge acquired in her first job? In general, former employees are not allowed to disclose this knowledge (e.g., customers data) if it qualifies as a trade secret, whereas they are allowed to do so, if it is part of their "general skill and knowledge." In drawing the line between "trade secrets" and "general skill and knowledge," law makers must balance the opposing goals of encouraging investment in knowledge and protecting job mobility, which is at the base of free competition. $^{7}$

\footnotetext{
${ }^{5}$ The US Economic Espionage Act, which criminalises TS misapproprition, defines the latter as: "all forms and types of financial, business, scientific, technical, economic, or engineering information, including patterns, plans, compilations, program devices, formulas, designs, prototypes, methods, techniques, processes, procedures, programs, or codes, whether tangible or intangible, and whether or how stored, compiled, or memorialized physically, electronically, graphically, photographically, or in writing" (§1839).

${ }^{6}$ See Backer-McKenzie (2013). This feature is explicitly acknowledged by the Directive proposal of the European Commission (Proposal 2013/0402).

${ }^{7}$ In some jurisdictions, courts just assume - under the doctrine of "inevitable disclosure" - that
} 
Similar considerations arise with respect to the covenants not to compete after the termination of the employment relationship. Californian courts tend not to enforce them at all, whereas other courts take a more cautious stance (usually based on "reasonableness" criteria). Clearly, where non-competition covenants are enforced, the primary producer of the know-how is protected (she must spend less to retain her employees, and she can share information internally more easily), but diffusion of the knowledge is stymied. ${ }^{8}$

Although outright theft of documents is obviously unlawful, other forms of information acquisition may or may not be lawful depending on circumstances and jurisdictions. In the famous du Pont vs. Christopher case, a company hired a pilot to take aerial pictures of a newly built plant, with the purpose of uncovering information about the rival's manufacturing process. ${ }^{9}$ The court held that this conduct was an improper method for the acquisition of information of the rival's production technique. While recognising that "for our industrial competition to remain healthy there must be breathing room for observing a competing industrialist," it concluded: "Our tolerance of the espionage game must cease when the protections required to prevent another's spying cost so much that the spirit of inventiveness is dampened. [...] To require DuPont to put a roof over the unfinished plant to guard its secret would impose an enormous expense to prevent nothing more than a school boy's trick." In the Christopher decision, the main arguments for the prohibition of the conduct relied on the cost of self-protection and the adverse impact of the conduct on inventiveness. ${ }^{10}$ These elements are formalised in the model below, which investigates the impact of costs and market structure on the optimal policy.

In this paper, we focus on the case in which the secret information provides a competitive advantage to its owner, who has no interest in sharing it. Once the

this transfer of proprietary knowledge cannot be avoided under the new duties taken up by the employee. See, for example, PepsiCo, Inc. v. Redmond, 54 F. 3d 1262, 1263-64 (7th Circuit 1995). Along the same line, mobility of groups of employees is subject to specific restraints. In some jurisdictions, soliciting the departure of employee teams or departments from rival firms (so called "poaching" or "raiding") is explicitly forbidden. In others, e.g., in California, it is not. California's high-tech companies have reacted by agreeing not to solicit each other's employees. This practice, however, has been considered anticompetitive by the antitrust authority. Complaint, US v. Adobe Systems Inc., et al., DOJ, 2010.

${ }^{8}$ California's exceptional labour mobility has been pointed out as a major driving force behind the success of the Silicon Valley's district (see Saxenian 1994). Gilson (1999) underscores the role served by California's lax trade secrets law with respect to labour mobility.

${ }^{9}$ E.I du Pont deNemours \& Co. v. Christopher, 431 F.2d 1012 (5th Cir. 1970).

${ }^{10}$ To put a roof over a plant to protect the secrets is an unreasonable request, not to put documents in the trash is considered a reasonable measure to keep them secret. In most countries, dumpster diving (searching in the trash for informative documents) is a lawful activity. 
information/know-how is obtained by the innovator, a rival firm invests resources to ferret it out. At the same time, the innovator invests to protect it. This secrecy contest determines the probability by which knowledge spills from one firm to the other, and hence the probability that the market shifts from monopoly to duopoly. TS law complements the effort of the innovator to keep the information secret. By reducing the probability of information leakage, TS law decreases the (wasteful) expenditure of the firms in the secrecy contest and harms competition. On this account, strong TS law might not be desirable. In a dynamic perspective, one should also consider that the "rent" granted by strong TS law to the secrecy holder provides incentives to the creation of knowledge, to the benefit of final consumers. In this respect, the optimal scope of TS law substantially depends upon how sensitive innovation production is to changes in the payoff to the innovator.

In Section 2, we formally derive the three effects mentioned above. An increase in TS protection: i) encorages the creation of innovative knowledge ("innovation effect"), ii) reduces the private expenditure in the secrecy contest ("expenditure effect"), and iii) increases the probability that the market is monopolised by the innovator ("competition effect"). The optimal policy should balance benefits and costs attendant with these effects.

Several factors affect the optimal policy choice. First, if the creation of innovation is very sensitive to changes in the payoff to the innovator (high elasticity of supply of innovation), then maximal TS protection is optimal. If the elasticity of supply of innovation is small - or nil - then the optimal policy will be guided by the other two factors: expenditure effect vs. competition effect. We show that the expenditure effect is likely to dominate if the cost of self protection for the innovator is low and cost of extraction for the rival is high. Under these conditions, the expenditure effect has a large weight in social welfare and maximal protection is preferable.

In general, when the cost of self-protection is high and cost of extraction is low, the case for TS protection is weaker. In the limit case in which the extraction cost is negligible, the optimal scope for legal protection is definitely narrower. This specification of our model captures those situations in which innovation lies on the face of the product and only legal protection can prevent imitation (unfair competition/passing off, see Section 3).

In the model, we take the intensity of competition upon duplication as given and allow duopoly prices to range from perfect competition prices (Bertand competition) to monopoly prices (collusion). This allows us to analyse the impact of competition intensity on the optimal TS policy. We show that the relationship between com- 
petition intensity and optimal TS protection is non-monotonic: maximal protection is optimal when competition is either very weak (collusion) or very intense (perfect competition). In the first case, the social gains from imitation are negligible: leakage of the secret does not bring any benefit to the consumers. So maximal TS protection is optimal. When competition is very intense and duopoly profits are very low, the rival has very weak incentives to extract the secret, while the innovator has very strong incentives to protect it. In this case, the impact of TS policy on the secrecy expenditure is relatively large (legal protection substitutes for self -protection) while the impact on market structure is small. Again, maximal protection is desirable. When competition is neither too strong nor too weak, the consumer's gain from imitation outweighs the expenditure effect and the optimal scope of TS law is narrower.

Finally, we consider the impact of horizontal product differentiation. We show that when the rival supplies a differentiated product, TS protection should be reduced. Here, the benefits to the consumers from duplication are so large and the secrecy expenses so low, that the case for secrecy loses much of its weight. This result is in line with the law of those jurisdictions (e.g., Germany and Austria), in which an assessment of the degree of similarity of the products generally accompanies misappropriation cases (de Vrey 2006).

The economic literature is limited on trade secret law and on unfair competition in general. In their pioneering article, Posner, Landes and Friedman (1991) defend trade secrets law on two grounds. On the one hand, trade secrets law complements patent law by protecting those inventions that firms choose not to patent (either because they fail to meet the patentability requirements or because patenting is too expensive). ${ }^{11}$ On the other hand, TS law allows firms to reduce the investment in self-protection (a feature captured by our model). Their analysis does not focus on the role played by self-protection and extraction costs, and market structure on the optimal policy.

Rønde (2001) investigates the effect of TS law on the organisational structure of firms. In his model, firms can divide production into independent tasks to limit knowhow leakage due to labour mobility. He shows, among other things, that the benefits of reducing the information sharing are greatest if the competition in the market is neither very tough nor very weak. Fosfuri and Rønde (2004) analyse the impact of TS law both on the extent of knowledge spillover (through labour mobility) and on

\footnotetext{
${ }^{11}$ Over the last decade, substantial research has been devoted to the patent / secrecy choice, both from an empirical and theoretical perspective (see the review of Hall et al. (2014)). This literature, however, is of tangential interest to us, as we focus on TS as a standalone branch of the law.
} 
the incentives of firms to cluster in the same area (to benefit from the spillover, at the cost of more intense product competition). In their model, the strength of TS law is measured by the size of the damages awarded to the first innovator, when a worker moves to a rival firm to develop a follow-up innovation. Without affecting the size of the spillover, high damages reduce the wage earned by the worker and provide firms with incentives to cluster together. Hence, they increase social welfare. The effect of strong TS law would not necessarily be positive, however, if TS law reduced labour mobility (which is the case, for example, when injunctive relief is granted to the innovating firm or when covenants not to compete are enforced by the courts). In our model, we implicitly focus on the latter case by assuming that TS law affects the probability that knowledge spills from the innovator to a second (non-innovating) firm.

\section{The model}

The models is built on the assumption that one firm, labelled "innovator," can invest in the creation of innovative knowledge. This knowledge allows him to produce a new product and obtain supercompetitive profits. A second firm (labeled "rival") has the capacity to produce the same product, if it gains access to this knowledge. So a secrecy contest takes place, in which the rival invests resources to extract information from the innovator, while the innovator invests resources to protect it. The structure of the secrecy contest is affected by TS law: given the efforts of the two firms, the probability that information leaks is smaller if the law offers stronger protection. When information leaks, the market turns into a symmetric duopoly. ${ }^{12}$

The probability that information leaks from the innovator to the rival is:

$$
\text { probability of leakage }=(1-\tau) \lambda\left(x_{I}, x_{R}\right)=(1-\tau) \frac{x_{R}}{x_{I}+x_{R}},
$$

where $x_{I}$ is the effort exerted by the innovator and $x_{R}$ is the effort exerted by the rival. $\tau \in[0,1]$ captures the strength of TS law: stronger TS law makes leakage less likely, given the efforts of the two parties. If TS law is very strong $(\tau=1)$, the probability of leakage is nil. If TS is very weak $(\tau=0)$, the probability of leakage only depends on the private efforts of the two parties $\left(p r\right.$. leakage $\left.=\lambda\left(x_{I}, x_{R}\right)=\frac{x_{R}}{x_{I}+x_{R}}\right)$.

The payoff to the innovator once she has obtained the secret knowledge is:

$$
\pi_{I}\left(x_{I}, x_{R}\right)=\left[1-(1-\tau) \lambda\left(x_{I}, x_{R}\right)\right] \pi_{m}+(1-\tau) \lambda\left(x_{I}, x_{R}\right) \pi_{d}-c x_{I} .
$$

\footnotetext{
${ }^{12}$ The model can be suitably extended so as to allow for a plurality of duplicators. The qualitative analysis remains unaffected. Similarly, the analysis can be extended to allow for an innovation race between firms.
} 
With probability $\left[1-(1-\tau) \lambda\left(x_{I}, x_{R}\right)\right]$ secret information is retained and the innovator earns monopoly profits $\pi_{m}$. With probability $(1-\tau) \lambda\left(x_{I}, x_{R}\right)$ information leaks to the rival and the innovator earns duopoly profits $\pi_{d}$. The cost of self-protection amounts to $c x_{I}$.

The payoff to the rival is

$$
\pi_{R}\left(x_{I}, x_{R}\right)=(1-\tau) \lambda\left(x_{I}, x_{R}\right) \pi_{d}-s x_{R} .
$$

With probability $(1-\tau) \lambda\left(x_{I}, x_{R}\right)$ the rival ferrets the secret information out and enters the market, where he obtains duopoly profits $\pi_{d}$. The effort to extract information $\operatorname{costs} s x_{R}$.

In the secrecy contest, the two players will optimally choose $x_{I}$ and $x_{R}$ to maximize their payoffs. In the Nash equilibrium of this contest, the following conditions hold:

$$
\left\{\begin{aligned}
-(1-\tau) \lambda_{x_{I}}^{\prime}\left(x_{I}, x_{R}\right)\left(\pi_{m}-\pi_{d}\right) & =c \\
(1-\tau) \lambda_{x_{R}}^{\prime}\left(x_{I}, x_{R}\right) \pi_{d} & =s .
\end{aligned}\right.
$$

Stronger TS protection (large $\tau$ ) makes leakage less likely, and hence reduces both the marginal benefit of self-protection and the marginal benefit of extraction.

Note that the marginal benefits of effort for the innovator and the rival are not the same. When the rival enters the market, the loss for the entrant tends to be greater than the gain for the rival: $\pi_{m}-\pi_{d}>\pi_{d}$ (which is true as far as $\pi_{m}>2 \pi_{d}$, is a condition that holds when products are not too different). The innovator, therefore, tends to have stronger incentives to invest in the secrecy contest than the rival. ${ }^{13}$ In line with the classic result of Gilbert and Newberry (1982), we call this observation the Persistence of secrecy.

Let $k_{I}=\frac{c}{\pi_{m}-\pi_{d}}$ be the relative self-protection cost for the innovator (cost as a share of gain from protection), and $k_{R}=\frac{s}{\pi_{d}}$ the relative extraction cost for the rival (cost as share of gain from extraction). From eqs. (3), we obtain the following equilibrium values:

$$
x_{I}^{*}=(1-\tau) \frac{k_{R}}{\left(k_{R}+k_{I}\right)^{2}}, \quad x_{R}^{*}=(1-\tau) \frac{k_{I}}{\left(k_{R}+k_{I}\right)^{2}},
$$

and

$$
\lambda\left(x_{I}^{*}, x_{R}^{*}\right)=\frac{k_{I}}{k_{R}+k_{I}}=\frac{c}{c+s\left(\frac{\pi_{m}}{\pi_{d}}-1\right)} \equiv \lambda^{*} .
$$

\footnotetext{
${ }^{13}$ Similarly, innovators will have greater incentives to lobby for favourable trade secrets legislation than will imitators. Innovators can offer greater salaries to their key employees than imitators can. The secrecy contest is symmetric if the two firms produce homogenous goods and collude on the market.
} 
In equilibrium, the probability of information leakage $(1-\tau) \lambda\left(x_{I}^{*}, x_{R}^{*}\right)$ depends on the strength of trade secrets law $\tau$, and on the relative costs in the secrecy contest. Given $\tau$, leakage is more likely if self-protection costs are higher $\left(\frac{\partial \lambda^{*}}{\partial c}>0\right)$, extraction costs are lower $\left(\frac{\partial \lambda^{*}}{\partial s}<0\right)$, monopoly profits are lower $\left(\frac{\partial \lambda^{*}}{\partial \pi_{m}}<0\right)$, and duopoly profits are higher $\left(\frac{\partial \lambda^{*}}{\partial \pi_{d}}>0\right)$.

Note, for future reference, that total secrecy costs amount to

$$
\begin{aligned}
c x_{I}^{*}+s x_{R}^{*} & =k_{I}\left(\pi_{m}-\pi_{d}\right)(1-\tau) \frac{k_{R}}{\left(k_{R}+k_{I}\right)^{2}}+k_{R} \pi_{d}(1-\tau) \frac{k_{I}}{\left(k_{R}+k_{I}\right)^{2}} \\
& =(1-\tau) \pi_{m} \frac{k_{I} k_{R}}{\left(k_{R}+k_{I}\right)^{2}}=(1-\tau) \pi_{m} \lambda^{*}\left(1-\lambda^{*}\right) .
\end{aligned}
$$

As in standard rent-seeking games, total secrecy costs are smaller if the two contestants are strongly asymmetric $\left(\lambda^{*}\right.$ close to 1 or $\lambda^{*}$ close to 0$)$.

A marginal increase in the strength of TS law reduces the amount of resources wasted in the secrecy contest by an amount proportional to $\pi_{m} \lambda^{*}\left(1-\lambda^{*}\right) \cdot{ }^{14}$

Let us move now to the first stage of the game, in which the innovator invests to obtain the new piece of knowledge. From an ex-ante perspective, the expected profit to the innovator is:

$$
\Pi_{I}=z \pi_{I}\left(x_{I}^{*}, x_{R}^{*}\right)-d(z),
$$

where $\pi_{I}\left(x_{I}^{*}, x_{R}^{*}\right)$ is the expected profit that she obtains upon discovery (eq. 1), $z$ the probability of discovery and $d(z)$ the discovery costs, with $d^{\prime}>0$ and $d^{\prime \prime} \leq 0$.

Thus, the optimal creation effort $z^{*}$ solves

$$
\pi_{I}\left(x_{I}^{*}, x_{R}^{*}\right)=d^{\prime}\left(z^{*}\right) .
$$

By implicit differentiation, we obtain $\frac{\partial z^{*}}{\partial \tau}>0$. Stronger TS law increases the innovation effort. ${ }^{15}$

We can now turn to optimal policy. In this simple set-up, ex-ante social welfare is

$$
S W=z^{*}\left\{\left[1-(1-\tau) \lambda^{*}\right] W_{m}+(1-\tau) \lambda^{*} W_{d}-c x_{I}^{*}-s x_{R}^{*}\right\}-d\left(z^{*}\right),
$$

where monopoly total surplus is $W_{m}=\pi_{m}+C_{m}$ (profits + consumer surplus), and duopoly total surplus is $W_{d}=2 \pi_{d}+C_{d}$ (profits + consumer surplus). Trade secrets

\footnotetext{
${ }^{14}$ Note that the "rent seeking" specification of the secrecy contest implies that an increase in $\tau$ induces the same percentage reduction of $x_{I}^{*}$ and $x_{R}^{*}$.

${ }^{15}$ More precisely, $\frac{\partial z^{*}}{\partial \tau}=\frac{\lambda^{*}\left(\pi_{m}-\pi_{d}\right)+\frac{1}{k_{R}+k_{I}}\left(1-\lambda^{*}\right) c}{d^{\prime \prime}\left(z^{*}\right)}$.
} 
law affects the self-protection and extraction efforts $x_{I}^{*}$ and $x_{R}^{*}$, the resulting probability of leakage $(1-\tau) \lambda^{*}$, and, in turn, the probability that knowledge is created, $z^{*}$.

We have

$$
\begin{aligned}
\frac{\partial S W}{\partial \tau} & =\frac{\partial z^{*}}{\partial \tau}\left\{\left[\left(1-(1-\tau) \lambda^{*}\right) W_{m}+(1-\tau) \lambda^{*} W_{d}-c x_{I}^{*}-s x_{R}^{*}\right]-d^{\prime}\left(z^{*}\right)\right\} \\
& -z^{*} \lambda^{*}\left(W_{d}-W_{m}\right)-z^{*} \frac{\partial}{\partial \tau}\left(c x_{I}^{*}+s x_{R}^{*}\right) .
\end{aligned}
$$

The first term represents the welfare gain due to additional innovation effort, the second the welfare loss due to the increased likelihood of monopoly, and the last the welfare gain due to reduced secrecy expenditure.

In view of eqs. (6), (1), and (4), we get

$$
\begin{gathered}
\frac{\partial S W}{\partial \tau}=\frac{\partial z^{*}}{\partial \tau}\left\{\left(1-(1-\tau) \lambda^{*}\right) C_{m}+(1-\tau) \lambda^{*}\left(C_{d}+\pi_{d}\right)-s x_{R}^{*}\right\} \\
-z^{*} \lambda^{*}\left(W_{d}-W_{m}\right)+z^{*} \pi_{m} \lambda^{*}\left(1-\lambda^{*}\right),
\end{gathered}
$$

that is, in view of $(2)$

$$
\begin{gathered}
\frac{\partial S W}{\partial \tau}=\frac{\partial z^{*}}{\partial \tau}\left\{\left(1-(1-\tau) \lambda^{*}\right) C_{m}+(1-\tau) \lambda^{*} C_{d}+\pi_{R}\left(x_{I}^{*}, x_{R}^{*}\right)\right\} \\
-z^{*} \lambda^{*}\left(W_{d}-W_{m}-\pi_{m}\left(1-\lambda^{*}\right)\right) .
\end{gathered}
$$

An increase in TS protection stimulates innovation, hinders diffusion, and reduces secrecy costs. ${ }^{16}$ The net effect is captured by the following proposition.

Proposition 1 Stronger TS protection is socially desirable if, and only if, the following holds:

$$
\begin{gathered}
\underbrace{\frac{\partial z^{*}}{\partial \tau} \frac{1}{z^{*}}\left\{\left(1-(1-\tau) \lambda^{*}\right) C_{m}+(1-\tau) \lambda^{*} C_{d}+\pi_{R}\left(x_{I}^{*}, x_{R}^{*}\right)\right\}}_{\text {innovation effect }} \\
+\underbrace{\lambda^{*}\left(1-\lambda^{*}\right) \pi_{m}}_{\text {expenditure effect }}-\underbrace{\lambda^{*}\left(W_{d}-W_{m}\right)}_{\text {competition effect }}>0 .
\end{gathered}
$$

This formula has a simple explanation. The first term captures the ex-ante effect: an increase in TS protection stimulates the creation of innovative knowledge. A small increase in $\tau$ induces a percentage increase in the probability of innovation equal to

\footnotetext{
${ }^{16}$ Social welfare is concave in $\tau$.
} 
$\frac{\partial z^{*}}{\partial \tau} \frac{1}{z^{*}}$. In turn, this creates an innovation surplus equal to the "externality" that the innovator exerts on the rival and the consumers. The gain accruing to the innovator himself does not matter, because it is perfectly balanced, at the margin, by the increase in innovation expenditure. This innovation surplus is higher if larger surplus is netted by consumers on the market ( $C_{m}$ under monopoly, $C_{d}$ under duopoly), and if the rival obtains a larger payoff (expected profits less extraction expenditure).

The second term represents the gain due to the reduction in private expenditure in the secrecy game. This gain tends to be small when the secrecy contest is very asymmetric, i.e. when $\lambda^{*}$ is close to one or nil.

Finally, the competition effect captures the loss due to the reduced probability that the market shifts from monopoly to duopoly. This depends on the likelihood of leakage in the absence of legal protection, $\lambda^{*}$, and on the intensity of competition upon duplication. This term collapses to nil if private protection alone is fully effective $\left(\lambda^{*} \rightarrow 0\right)$, or if the rival and the innovator produce fungible goods and collude on prices (market welfare under duopoly $W_{d}=$ market welfare under monopoly $W_{m}$ ).

The innovation effect is large if innovation is sensitive to policy changes. In turn, this depends on shape of the innovation $\operatorname{cost} d(z)$ and the impact of the policy variable $\tau$ on the payoff to the innovator. If, for simplicity, we take an isoelastic cost function: $d(z)=\frac{1}{\alpha} z^{\alpha}$, with $\alpha>1$, we get: $z^{*}=\pi_{I}\left(x_{I}, x_{R}\right)^{\frac{1}{\alpha-1}}$ and

$$
\frac{\partial z^{*}}{\partial \tau} \frac{1}{z^{*}}=\frac{1}{\alpha-1} \frac{\partial \pi_{I}\left(x_{I}, x_{R}\right)}{\partial \tau} \frac{1}{\pi_{I}\left(x_{I}, x_{R}\right)} .
$$

The semielasticity of innovation is equal to the percentage increase in the innovator's expected profits (upon discovery) due to a small increase in TS protection, times a factor $\frac{1}{\alpha-1}$ which depends on the elasticity $\alpha$ of the cost function (in turn, $\alpha$ is the inverse of the elasticity of the supply of innovation with respect to the research expenditure). So, if the cost function is very elastic (or if the supply of innovation is very inelastic), $\frac{\partial z^{*}}{\partial \tau} \frac{1}{z^{*}}$ goes to nil. As the supply of innovations becomes more elastic (small $\alpha$ ), the innovation effect becomes larger. ${ }^{17}$

The surplus created by the innovation depends on $\tau$. If legal protection is weak, the surplus is larger. This is intuitive, as a small $\tau$ benefits (ex-post) both the consumers

\footnotetext{
${ }^{17}$ Empirical estimates of the elasticity of the supply of innovation are reviewed by Denicolò (2007). Note that $\frac{\partial \pi_{I}\left(x_{I}, x_{R}\right)}{\partial \tau}=\lambda^{*}\left(\pi_{m}-\pi_{d}\right)+\frac{1}{k_{R}+k_{I}}\left(1-\lambda^{*}\right) c$, which is independent of both $z$ and $\tau$. Finally, note that $\frac{\partial z^{*}}{\partial \tau} \frac{1}{z^{*}}$ would be larger if innovation were the outcome of a race between firms. In that case, stronger TS protection would increase the reward to the winner of the race and, simultaneously, reduce the reward to the loser of the race. Both effects boost the incentives to invest in innovation.
} 
and the rival. Thus, as $\tau$ increases, the share of the surplus appropriated by the innovator increases, and the cause for legal protection decreases. The innovation surplus is always positive, and it increases with $\lambda^{*}$.

Whether the optimal policy choice $\tau^{*}$ lies on the interior or on the boundary $\left(\tau^{*}=0, \tau^{*}=1\right)$ depends on the relative weight of the three effects. We know that the optimal policy certainly involves maximal protection if the expenditure effect exceeds the competition effect, i.e. if strong TS protection is optimal even from an ex-post perspective. This case arises when the saving in self-protection/extraction expenditure outweighs the reduction in market surplus brought about by an increase in $\tau$. In this case, the justification for TS protection overlaps with the rationale normally provided for rules against theft, which posit that, in the absence of such rules, individuals would spend an excessive amount of resources in protection and extraction activities [see, for instance, Posner (2007)]. ${ }^{18}$

In our setting, "theft" concerns a special good - knowledge- which tends to be non rival. So, the social gain due to the (involuntary) transfer of the asset is calculated on the basis of the welfare associated with different market configurations (duopoly vs. monopoly).

Below, we focus on those cases in which strong TS is optimal from an ex-post perspective (and thus, a fortiori, from an ex-ante perspective). In general, this is more likely to arise when competition in the duopoly market is weak (so that $W_{d}-W_{m}$ is small) and the innovator has the upper hand in the secrecy contest ( $\lambda^{*}$ is small) (see eq. 10). The latter case arises when the protection cost $c$ is small and the extraction cost $s$ is large: knowledge can be effectively protected and, even without TS law, duopoly is unlikely to materialize.

From an ex-ante perspective (including the incentive effect), the optimal policy will be on the interior or on the boundary depending on the weight of the three effects. The incentive effect brings the justification of TS law closer to that normally offered to intellectual property law. TS law differs, in our model, because it directly impacts the amount of resources parties invest in the secrecy contest.

Below, we provide more structure to market competition .

\section{Case 1: Homogeneous goods.}

Let us consider the case in which the goods produced by the two firms are perfect substitutes. The inverse demand function is: $p=1-Q$. Marginal production costs

\footnotetext{
${ }^{18}$ We are grateful to editor Scott Baker for this observation.
} 
are set to zero. Under monopoly, output is $Q_{m}=\frac{1}{2}$, profits are $\pi_{m}=\frac{1}{4}$ and consumer surplus is $C_{m}=\frac{1}{8}$.

Under duopoly, the output level $Q_{d}$ depends on the intensity of competition between the firms (upon entry). In order to capture different outcomes, let: $Q_{d}=k$, with $k \in\left[\frac{1}{2}, 1\right]$. For $k=1 / 2$, we get the collusive outcome, for $k=2 / 3$, Cournot competition, and for $k=1$, Bertrand competition. For us, Bertrand competition is only a limit case: if the rival expects zero duopoly profits, he will not spend resources to ferret the secret out. Duopoly profits are: $\pi_{d}=\frac{1}{2} k(1-k)$, and consumer surplus is: $C_{d}=\frac{1}{2} k^{2}$.

Ex-post social welfare $\overline{S W}$ (once knowledge has been created) increases with $\tau$ if, and only if, the competition effect is smaller than the expenditure effect, $\lambda^{*}\left(W_{d}-W_{m}\right)<$ $\lambda^{*}\left(1-\lambda^{*}\right) \pi_{m}$, i.e. if

$$
(1-k) k+\frac{k^{2}}{2}-\frac{1}{4}-\frac{1}{8}<\left(1-\frac{c}{c+s\left(\frac{1 / 4}{1 / 2 k(1-k)}-1\right)}\right) \frac{1}{4}
$$

This inequality is more likely to be met if the protection cost $c$ is small and the extraction cost $s$ is large (so that $\lambda^{*}$ is small). If (11) is met, the (ex-post) optimal policy entails maximal TS protection.

The relationship between the intensity of competition $k$ and the optimal (ex-post) policy is non-monotonic, as shown by Figure 1 below (which assumes that $s=\frac{1}{4} c$ ). Minimal protection is warranted (ex-post) for intermediate levels of competition. Maximal protection is warranted otherwise (note that ex post social welfare is linear in $\tau$ ). Several factors are at work.

First, when competition is strong $(k \rightarrow 1)$, information leakage provides great benefits to the consumers $\left(W_{d}-W_{m}\right.$ is large). However, since duopoly profits are low, the rival has little to gain from the extraction of the secret, the extraction effort is low and the benefits of leakage tend to materialize with small probability (small $\left.\lambda^{*}\right)$. The competition effect tends to be small. The small extraction effort tends to reduce also the secrecy expenditure. However, the latter effect is countered by the increase in the protection effort of the innovator, who stands to lose more when competition is strong. So, while both the competition and expenditure effects will be low, the latter will be relatively larger and inequality (11) will be met $\left(\frac{1}{2}-\frac{1}{4}-\frac{1}{8}<\frac{1}{4}\right)$.

When competition is very weak $(k \rightarrow 1 / 2)$, information leakage provides a very small gain to the consumes ( $W_{d}-W_{m}$ is small). The competition effect will be very small, while the expenditure effect will not. Hence, maximal protection is desirable $\left(0<\frac{s}{c+s}\right)$. 
For intermediate levels of $k$, the competition effect is sizable and minimal protection may be desirable. This occurs, however, only if the probability of disclosure in the absence of legal protection $\left(\lambda^{*}\right)$ is sufficiently large, i.e. only if the protection cost $c$ is large and the extraction cost $s$ is small

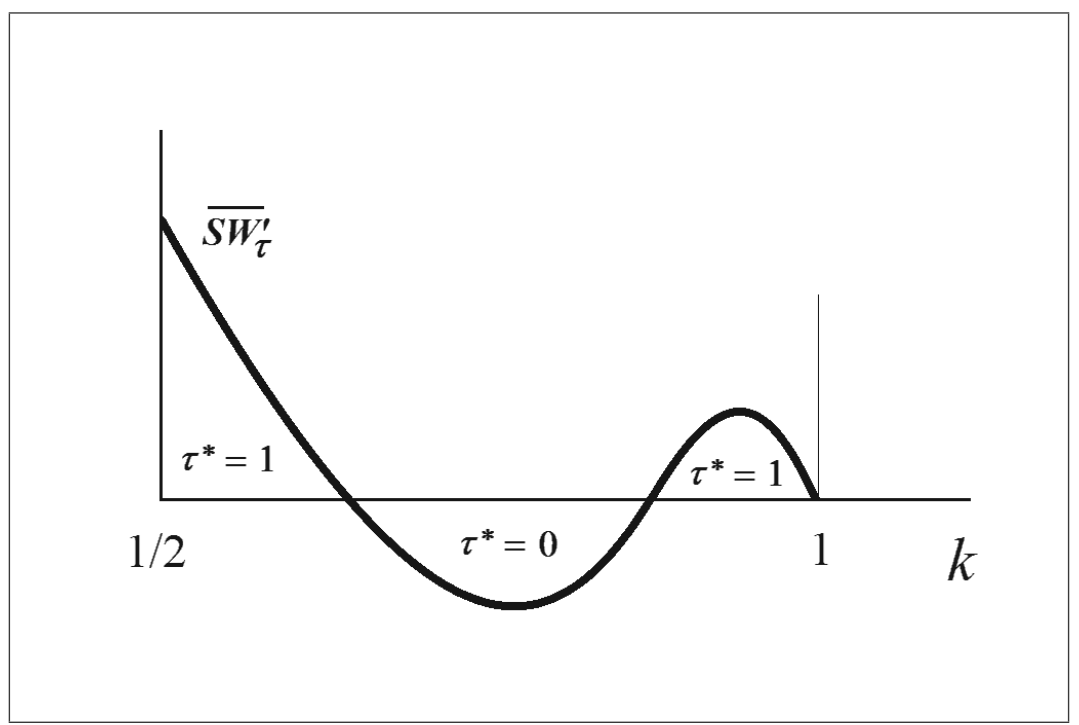

Fig. 1. Intensity of competition and ex-post desirability of stronger TS protection.

In the special case of Cournot competition $\left(k=\frac{2}{3}\right)$, minimal protection is optimal ex-post if, and only if, $s<\frac{4}{13} c$.

If maximal protection is desirable ex-post, it will a fortiori be so ex-ante (taking the innovation incentives into account). The weight of the innovation effect depends on the elasticity of the supply of innovation $(1 / \alpha)$.

In Figure 2, we fix $\alpha=2$ and posit that $s$ is sufficiently small to make minimal protection optimal ex post $(s=0.01, c=1)$. Optimal TS protection depends on the intensity of competition $k$ as follows. 


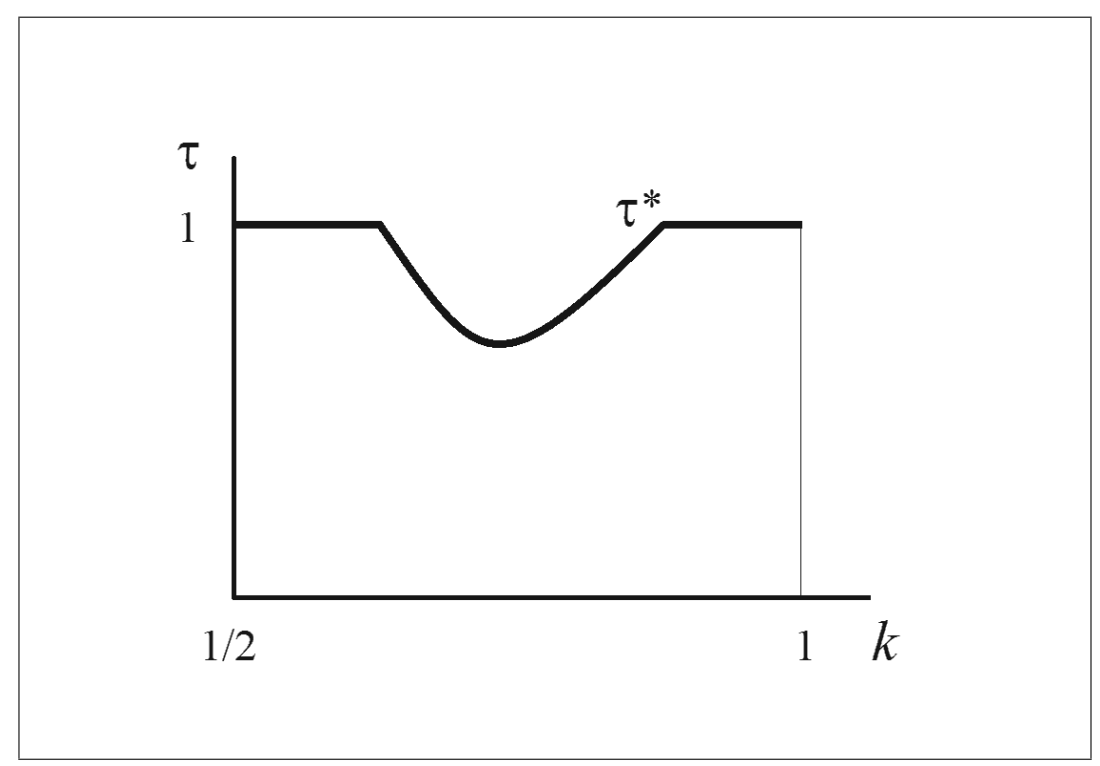

Fig. 2. Optimal TS scope given intensity of competition.

Optimal TS scope is maximal both for low levels and high levels of competition, for the reasons explained above. Non-maximal TS protection is optimal only for intermediate levels of $k$, in which the competition effect is sufficiently large. ${ }^{19}$

The next example generalises the insights obtained to the case of horizontally differentiated goods.

\section{Case 2: Product differentiation}

Let us consider the case where the rival is able to supply a product that is different from that supplied by the innovator, and neither product dominates the other one.

Let the inverse demand functions faced by the innovator and the rival be, respectively,

$$
p_{1}=1-q_{1}-(1-\beta) q_{2}, \quad \text { and } \quad p_{2}=1-q_{2}-(1-\beta) q_{1},
$$

where $\beta \in[0,1]$ is a parameter that captures the degree of product differentiation. ${ }^{20}$

For $\beta=1$, the two goods are perfectly differentiated. In fact, they are independent of each other. This implies that there is no competition between the innovator and the rival: both producers are monopolists on their own market. For $\beta=0$, the

\footnotetext{
${ }^{19}$ With quadratic innovation costs, optimal protection under Cournot competition $(k=2 / 3)$ is maximal for all combinations of $c$ and $s$. Non maximal protection can only be optimal if the supply of innovation is relatively inelastic $(\alpha<2)$.

${ }^{20}$ See Singh and Vives (1984). The case of complementary goods, which arises for $\beta>1$, is of no interest here. In fact, when goods are complements, the innovator is always better off if the rival enters the market. In this situation, stronger TS law (enforcement of non-disclosure agreements) facilitates technological transfer and hastens entry.
} 
goods are perfects substitutes (homogeneous goods). Production costs are set to 0. Consumer surplus is

$$
C S_{d}=\frac{1}{2}\left(1-(1-\beta) q_{2}-p_{1}\right)+\frac{1}{2}\left(1-(1-\beta) q_{1}-p_{2}\right)=(2-\beta) q_{1}^{2},
$$

while individual firm's profits are

$$
\pi_{d}=p_{1} q_{1}=p_{2} q_{2}=\left(1-(2+\beta) q_{1}\right) q_{1} .
$$

In the absence of imitation $\left(q_{2}=0\right)$, the innovator serves only the first market and $p_{m}=\frac{1}{2}, q_{m}=\frac{1}{2}, C S_{m}=\frac{1}{8}$, and $\pi_{m}=\frac{1}{4}$.

We concentrate on some important cases.

Collusion: Firms maximise their joint profits: $\pi_{1}+\pi_{2}=p_{1} q_{1}+p_{2} q_{2}$. The optimal quantities are $q_{1}=q_{2}=\frac{1}{2(2-\beta)}$, while the prices charged are $p_{1}=p_{2}=\frac{1}{2}$.

Cournot: Firms compete in quantities. By combining the best response functions, we get $q_{1}=q_{2}=\frac{1}{3-\beta}=p_{1}=p_{2}$. Equilibrium quantities are now larger than under collusion.

Bertrand. If firms compete in prices, we get: $p_{1}=p_{2}=\frac{\beta}{1+\beta}$, and $q_{1}=q_{2}=$ $\frac{1}{(2-\beta)(1+\beta)}$.

Firms profits are largest under Collusion and smallest under Bertrand. As goods become more differentiated, the three competition modes converge to the same outcome (two independent monopolies). Note that, as goods become more differentiated, our assumption of no-technology-licensing becomes more demanding (aggregate profits exceed monopoly profits), especially if competition is weak. ${ }^{21}$

Let us start again from the ex-post perspective. As in the homogenous goods case, the weight of the expenditure effect is larger if $\lambda^{*}$ is small, i.e. if the protection cost $c$ is small and the extraction cost $s$ is large. Let us concentrate on the impact of product differentiation.

As products become more differentiated, the gain from information extraction for the rival increases while the loss from disclosure for the innovator decreases. This implies that the rival spends more on extraction, while the innovator spends less in protection. In the limit, for $\beta \rightarrow 1$, the two markets become completely independent, leakage (in the absence of TS protection) tends to occur with the largest probability, $\lambda^{*} \rightarrow 1$, and the expenditure effect collapses to nil. The competition effect, on

\footnotetext{
${ }^{21}$ Suppose that the innovator licenses the innovation to the rival. If the intensity of competition is not affected by licensing (say, the licensing fee just allocates bargaining surplus according to a fixed sharing rule), then only the innovation effect remains, of our welfare analysis. Maximal TS protection is optimal because, by increasing the licensing fee, it enhances the incentives to innovate.
} 
the contrary, displays its maximal potential, as leakage provides great benefits to consumers. So, if goods are highly differentiated, minimal protection is optimal .

Both the competition and expenditure effects are largest under Bertrand and smallest under collusion. In the latter case, the benefits from duplication for the consumers are the least and stronger TS protection tends to be desirable ex-post. Figure 3 highlights the combinations of $c / s$ and $\beta$ that yield maximal or minimal TS protection.

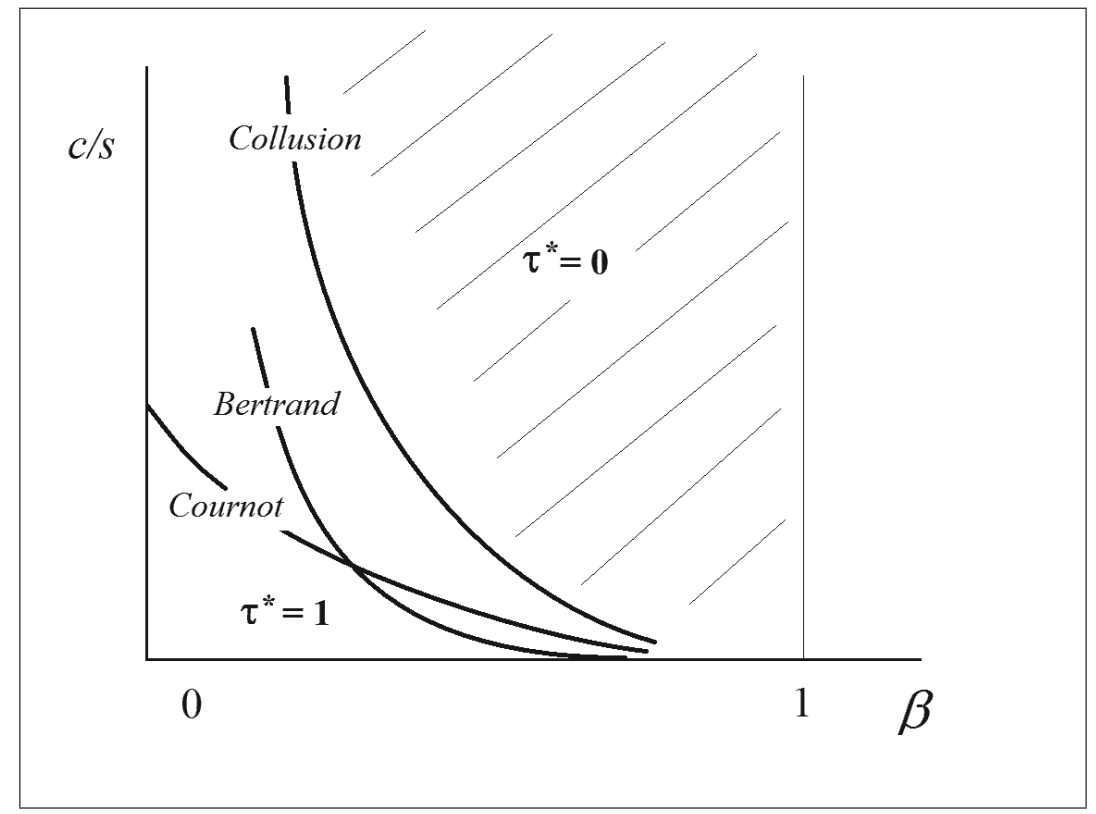

Fig. 3. Ex-post optimal TS scope given product differentiation and secrecy costs.

Note that, while the ex-post desirability of TS protection is clearly highest under Collusion, the ranking between Bertrand and Cournot depends on the level of product differentiation. For low levels of differentiation, strong TS protection is more likely to be desirable (ex-post) under price competition than under quantity competition. The opposite applies when products are highly differentiated.

Ex-ante perspective. Clearly, the ex-ante optimal legal protection $\tau^{*}$ will be maximal if $\tau=1$ is optimal ex-post (i.e. if products are weakly differentiated, protection costs are high and extraction costs are low).

Figure 4 plots the optimal scope of TS law as a function of product differentiation (given $s=0.01, \quad c=1$ ). 


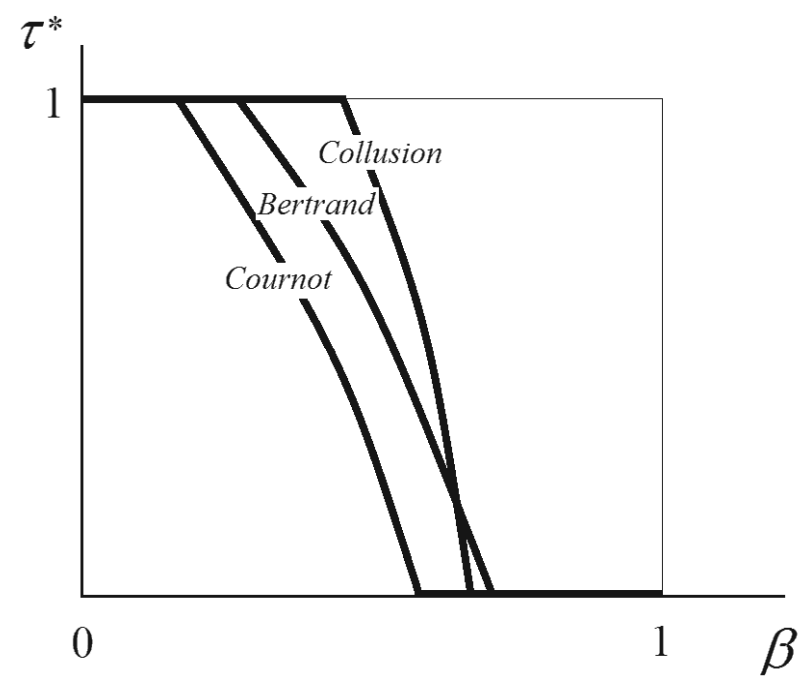

Fig. 4. Optimal TS scope given product differentiation.

The optimal scope of TS law becomes narrower as goods become more differentiated. Even if the innovation effect becomes larger as goods become more dissimilar (pushing for stronger TS protection), the competition effect prevails. Thus, as $\beta$ increases, $\tau^{*}$ (weakly) decreases. The optimal protection is higher under price competition (Bertrand) than under quantity competition (Cournot), since under the former the innovation surplus is larger. The optimal protection levels under Bertand and Collusion cross: for large levels of $\beta$, the small innovation surplus attendant with Collusion calls for weaker TS protection. ${ }^{22}$

\section{Unfair competition}

To disentangle further the factors driving optimal TS policy, let us consider the limit case in which innovative knowledge cannot be concealed: $s \rightarrow 0$. This case arises, for example, when the innovation lies on the face of the product. In the absence of legal provisions, the innovation immediately spills to the rival (for simplicity, we stick to the hypothesis that only one firm can imitate the product).

Provisions limiting outright imitation of products exist in many countries (under the heading of unlauterer Wettbewerb, concurrence déloyale, ongeoorloofde mededlinging, competenzia desleal, concorrenza sleale). ${ }^{23}$ Admittedly, British courts tend

\footnotetext{
${ }^{22}$ Social welfare under Betrand is the highest and is the most sensitive to variations in $\tau$.

${ }^{23}$ Since 1925, protection agains unfair competition has been part of the Paris Convention for the Protection of Industrial Property. Art. 10bis (2) stipulates "Any act of competition contrary to honest practices in industrial or commercial matters constitutes an act of unfair competition." In
} 
to apply a rather narrow version of unfair competition, mostly based on the tort of passing off (see Henning-Bodewig 2006, de Vrey 2006, and Ohly 2011). Most civil law countries have statues limiting copycat imitation of (well-established) products (parasitic copying, slavish imitation). These statutes create "quasi property rights" complementing traditional IP law. ${ }^{24}$

For $s \rightarrow 0$, we obtain: $x_{I}^{*}=0, x_{R}^{*}=(1-\tau) \frac{\pi_{m}-\pi_{d}}{c}$, and $\lambda^{*}=1$. Total secrecy expenditure, $c x_{I}^{*}+s x_{R}^{*}$, collapses to nil. The only obstacle to imitation is unfair competition law. ${ }^{25}$ The product is imitated with probability $1-\tau$. We have:

$$
\lim _{s \rightarrow 0} S W=z^{*}\left\{\tau W_{m}+(1-\tau) W_{d}\right\}-d\left(z^{*}\right),
$$

and (see 9):

$$
\lim _{s \rightarrow 0} \frac{\partial S W}{\partial \tau}=\frac{\partial z^{*}}{\partial \tau}\left\{\tau C_{m}+(1-\tau) C_{d}+(1-\tau) \pi_{d}\right\}-z^{*}\left(W_{d}-W_{m}\right) .
$$

This expression highlights the standard innovation/diffusion trade-off. Strong protection promotes inventiveness, but stymies competition.

Protection should be increased if, and only if,

$$
\underbrace{\frac{\partial z^{*}}{\partial \tau} \frac{1}{z^{*}}\left[\tau C_{m}+(1-\tau)\left(C_{d}+\pi_{d}\right)\right]}_{\text {innovation effect }}>\underbrace{W_{d}-W_{m}}_{\text {competition effect }}
$$

Note that now, from an ex-post perspective, minimal protection is always optimal.

With an isoelastic innovation cost function $\left(d(z)=\frac{1}{\alpha} z^{\alpha}\right)$, we obtain

$$
\frac{\partial S W}{\partial \tau}=\frac{1}{\alpha-1} \frac{\pi_{m}-\pi_{d}}{\tau \pi_{m}+(1-\tau) \pi_{d}}\left\{\tau C_{m}+(1-\tau) C_{d}+(1-\tau) \pi_{d}\right\}-\left(W_{d}-W_{m}\right) .
$$

If innovation is highly inelastic (large $\alpha$ ), the innovation effect is negligible and $\tau^{*}=0$. If innovation is highly elastic ( small $\alpha$ ), the innovation effect dominates and $\tau^{*}=1$.

particular, examples of unfair competition include "acts that create confusion with the activities of a competitor." This case is close to the common law tort of passing off.

${ }^{24}$ The British idiosyncrasy for these quasi-property rights has been vividly expressed by Justice Jacob: "There is no tort of copying. There is no tort of taking a man's market or customers. Neither the market nor the customers are the plaintiff's to own. There is no tort of making use of another's goodwill as such. There is no tort of competition" (Hodgkinson $\&$ Corby v. Wards Mobility Services, 1995, FSR 169). A rather different view is taken by the Austrian Supreme Court: "Anyone who without any achievement of his own, without creative effort of any consequence, adopts wholesale the unprotected achievement of another to compete with the injured party using the latter's own painstaking and expensive achievement acts dishonesly within the meaning of Sec. 1 of the Act Against Unfair Competition." (15/09/2005, 38 IIC 749, cited by Henning-Bodewig 2013).

${ }^{25}$ Note that our result does not bear on the issue of whether protection should be provided by means of IP law or unfair competition law. 
When the solution is on the interior, the optimal policy is given by

$$
\tau^{*}=\frac{\frac{1}{\alpha-1}\left(C_{d}+\pi_{d}\right)-\pi_{d} \frac{W_{d}-W_{m}}{\pi_{m}-\pi_{d}}}{\frac{1}{\alpha-1}\left(C_{d}-C_{m}\right)+\left(W_{d}-W_{m}\right)} .
$$

The optimal policy for the case with homogenous goods and quadratic innovation costs $(\alpha=2)$ is shown in Figure 5. The optimal policy is contrasted with the optimal policy of the previous section (trade secrecy). In the absence of a secrecy contest, $\tau$ affects social welfare only through the innovation and competition effects.

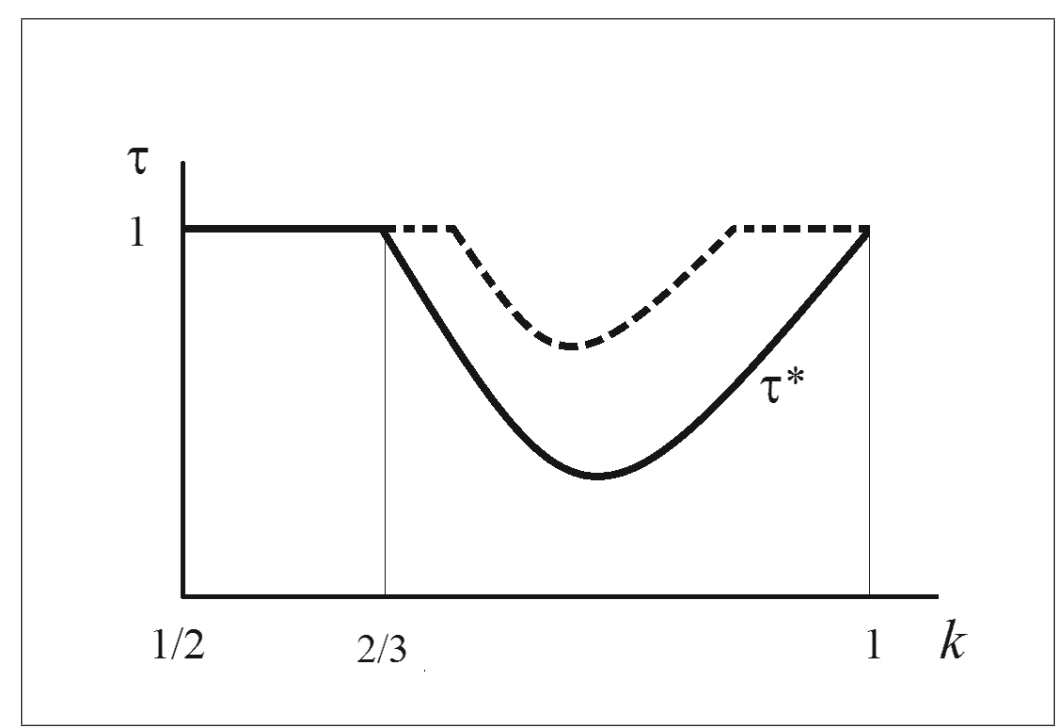

Fig. 5. Optimal protection against imitation vs. optimal TS protection (dashed).

The optimal scope of unfair competition law (passing off) is substantially narrower. Again, the relationship between $k$ (intensity of competition) and $\tau^{*}$ (optimal protection) is U-shaped.

The optimal policy entails $\tau^{*}=1$ for $k \leq 2 / 3$. With quadratic innovation costs, copycat imitation is socially beneficial only if competition is more intense than under Cournot.

Under product differentiation, a similar result arises. Optimal protection is narrower if the secrecy contest is absent. Figure 6 shows the case of Cournot competition (Bertrand and Collusion follow similar patterns). 


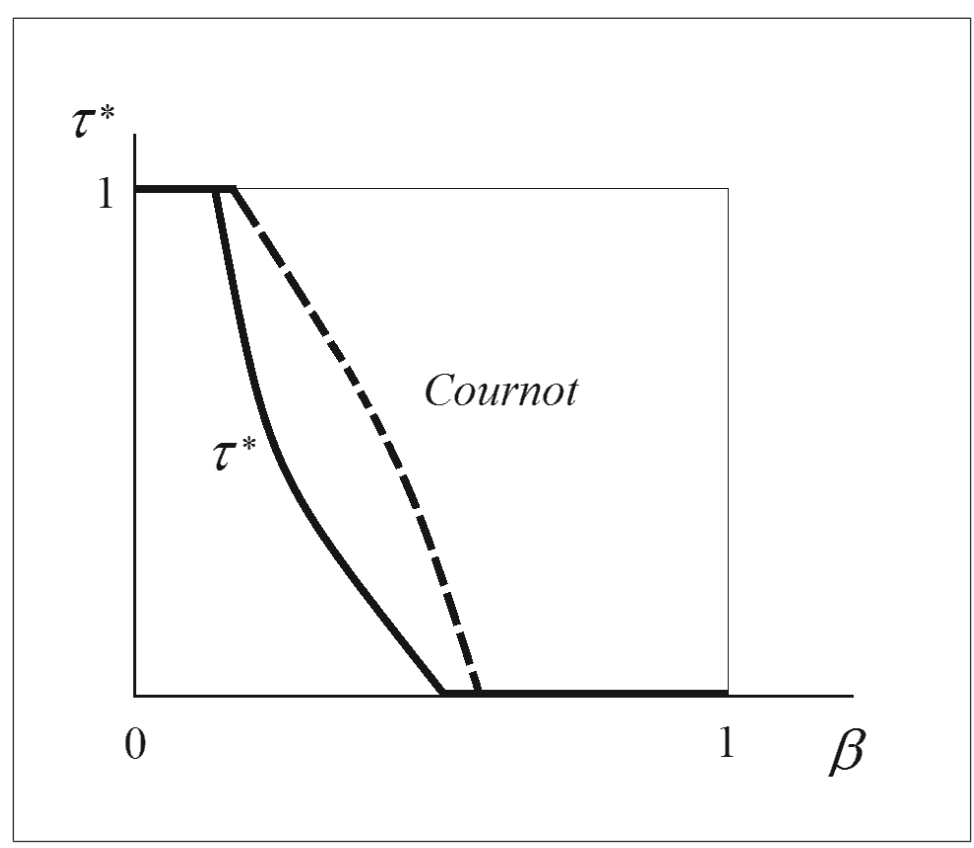

Fig. 6. Optimal scope of unfair competion law given product differentiation.

Also in the simple unfair competition scenario, the optimal policy scope decreases with the degree of product differentiation: protection against imitation should be stronger when the product of the rival is a copy-cat duplication of the product of the innovator. This is remarkably in line with the legislation of most EU countries.

\section{Conclusion}

Our model sheds light on benefits and costs of TS law. In particular, we show that TS law: i) reduces the expenditure of the parties in the secrecy contest, ii) it encourages the creation of knowledge by increasing the payoff to innovative firms, and iii) it hinders the diffusion of innovative knowledge in society and, thus, limits competition. Our model shows that the proper balance between these effects depends on a variety of factors. In particular, we have shown that maximal TS scope is likely to be optimal when competition in the product market in either very week or very intense, the cost of self-protection is low, and the cost of information extraction is high. If the latter two conditions do not hold (i.e. if information spills easily from the innovator to the rival), TS law loses some if its bite: the competition effect tends to outweigh the expenditure effect and weaker protection tends to be optimal.

At the limit, when the innovation lies on the face of the product, the law can still provide some protection against imitation (prevention of "unfair competition"). The optimal scope of this protection, however, is limited. 
When the product supplied by the rival is (horizontally) differentiated, the optimal scope for protection is again limited. Product differentiation dilutes the incentives of the parties to invest in the secrecy contest. It enhances the benefits form imitation for the consumers and increases the gains from information diffusion.

The last result has interesting ramifications in the context of current law. In Germany, for example, cases in which the misappropriation of secrets leads to the introduction of goods that imitate those of the secret-owner are decided by considering, inter alia, the degree of similarity between the products. The chances that the aggrieved party succeeds in court are higher if the products are close to each other (see de Vrey 2006). This feature is in line with the results of our model.

Our model does not address several features of TS law that deserve recognition.

First, we have not considered the case in which the owner of the know-how intends to licence it to other firms. Here, by inhibiting third parties from using misappropriated knowledge,TS law complements contract law in facilitating technological transfers. ${ }^{26}$

Second, we have not considered the case in which firms can protect innovative knowledge by means of a plurality of legal tools. Stronger TS protection induces companies to rely more on secrecy and less on formal IP rights, when these are available. With respect to patents, this tends to generate a social cost. Patents require the disclosure of the invention and have a finite duration. They provide an exclusive right. Secrets can potentially last forever, and are not exclusive. In general, patents tend to provide incentives to innovate at a lower social cost than secrets, thanks to the winner-take-all effect (Denicolò and Franzoni 2010). Thus, one potential downside of strong TS protection is that it estranges firms from the patent system. ${ }^{27}$

Finally, one additional cost of secrecy lies with the risk of knowledge loss. This was a concrete possibility in the past, when the secrets (arcana) of the craft were tightly kept by the master. The case of the Stradivarius violins is paradigmatic. Stradivarius did not share the secrets of his workmanship. With his death, they were lost forever. ${ }^{28}$

\footnotetext{
${ }^{26}$ Lemley (2011) argues that this is the leading function of TS law.

${ }^{27}$ Trade secrets and patents are compared, under different scenarios, also in Denicolò and Franzoni (2012). See Hall et al. (2014) for a exhaustive review of the literature on the patent/trade secrecy choice.

${ }^{28}$ This example was suggested to us by Hans-Bernd Schaefer. Similarly, the method developed by mathematician Scipione del Ferro (1465-1526) to solve cubic equations is not yet known with certainty. In the 16th century, mathematicians gained their reputation in public competitions where they challenged each other. They generally would not reveal their solution methods (de Laat 2000).
} 


\section{Appendix}

Here we derive the optimal policy solution for the case in which innovation costs are quadratic: $d(z)=\frac{1}{2} z^{2}$.

1) Optimal TS scope in the homogenous goods case:

$$
\tau^{*}=\frac{-16 c^{3}(1-k)^{3} k^{4}\left(-5+15 k-16 k^{2}+4 k^{3}\right)}{-4 c k\left(1-2 k+2 k^{2}\right)^{2}\left(-3+20 k^{2}-33 k^{3}+16 k^{4}\right) s^{2}+\left(1-2 k+2 k^{2}\right)^{3}\left(7-12 k+8 k^{2}\right) s^{3}},
$$

where $k$ represents the intensity of market competition.

2) Optimal TS scope under differentiated goods, Bertrand competition:

$$
\begin{gathered}
256 c^{3} \beta^{3}\left(-4+9 \beta^{2}+2 \beta^{3}+5 \beta^{4}\right) \\
+s^{3}(1+\beta)^{2}\left(\beta+\beta^{3}-2\right)^{3}\left(12-12 \beta+3 \beta^{2}-14 \beta^{3}+7 \beta^{4}\right) \\
-8 c s^{2} \beta\left(\beta+\beta^{3}-2\right)^{2}\left(20-4 \beta-19 \beta^{2}-16 \beta^{3}-24 \beta^{4}+3 \beta^{6}\right) \\
\tau^{*}=\frac{+16 c^{2} s \beta^{2}\left(-104+44 \beta+162 \beta^{2}+29 \beta^{3}+100 \beta^{4}-141 \beta^{5}-30 \beta^{6}-61 \beta^{7}+\beta^{9}\right)}{\left(16 c \beta\left(\beta+\beta^{3}-2\right)\left(16 c^{2} \beta^{2}\left(3 \beta+\beta^{3}+2\right)+s^{2}\left(\beta+\beta^{3}-2\right)^{2}\left(2-\beta+3 \beta^{3}\right)\right)\right.} \\
+2 c s \beta\left(20+12 \beta-11 \beta^{2}+4 \beta^{3}-18 \beta^{4}-7 \beta^{6}\right)
\end{gathered}
$$

where $\beta$ measures the degree of product differentiation.

3) Optimal TS scope under differentiated goods, Cournot competition:

$$
\begin{gathered}
256 c^{3}\left(-25+56 \beta-21 \beta^{2}+2 \beta^{3}\right) \\
-s^{3}(3-\beta)^{2}\left(5-6 \beta+\beta^{2}\right)^{3}\left(23-34 \beta+7 \beta^{2}\right) \\
\tau^{*}=\frac{-16 c^{2} s\left(1885-6042 \beta+6423 \beta^{2}-2748 \beta^{3}+523 \beta^{4}-42 \beta^{5}+\beta^{6}\right)}{16 c\left(5-6 \beta+\beta^{2}\right)\left(16 c^{2}\left(-5-2 \beta+\beta^{2}\right)\right.} \\
+s^{2}\left(5-6 \beta+\beta^{2}\right)^{2}\left(3-10 \beta+3 \beta^{2}\right)+ \\
\left.2 c s\left(-85+12 \beta+126 \beta^{2}-60 \beta^{3}+7 \beta^{4}\right)\right)
\end{gathered}
$$

4) Optimal TS scope under differentiated goods, Collusion

$$
\tau^{*}=\frac{\left.+s^{3}(1-\beta)^{3}\left(12-20 \beta+7 \beta^{2}\right)+c^{2} s\left(-16+40 \beta-25 \beta^{2}+\beta^{3}\right)\right)}{\left.2 c(1-\beta)\left(-7 c s\left((1-\beta) \beta+c^{2}(1+2 \beta)+2 s^{2}(1-\beta)\right)^{2}(3 \beta-2)\right)\right)} .
$$




\section{References}

Arundel, A. (2001). The relative effectiveness of patents and secrecy for appropriation. Research Policy, 30(4), 611-624.

Backer-McKenzie (2013), Study on Trade Secrets and Confidential Business Information in the Internal Market, downloadable at http://ec.europa.eu/internal_market/ iprenforcement/trade_secrets/

Balasubramanian, N., and Sivadasan, J. (2011) What happens when firms patent? New evidence from US economic census data, Review of Economics and Statistics, 93, $126-46$.

DeLaat, P., (2000), Patenting mathematical algorithms: What's the harm? A thought experiment in algebra, International Law and Economcs Review, 20, 187-204.

Denicolò, V. (2007). Do patents over-compensate innovators? Economic Policy 22/52, 679-729.

Denicolò, V., and Franzoni, L. A. (2010). On the winner take-all principle in innovation races. Journal of the European Economic Association, 8(5), 1133-1158.

Denicolò, V., and Franzoni, L. A. (2012). Weak Intellectual Property Rights, Research Spillovers, and the Incentive to Innovate. American Law and Economics Review, 14(1), 111-140.

De Vrey, R. (2006), Towards a European Unfair Competition Law: A Clash Between Legal Families, Martinus Nijhoff Publishers, Leiden.

Fosfuri, A., and Rønde, T. (2004). High-tech clusters, technology spillovers, and trade secret laws. International Journal of Industrial Organization, 22(1), 45-65.

Gilbert, R. J., \& Newbery, D. M. (1982). Preemptive patenting and the persistence of monopoly. The American Economic Review, 514-526.

Gilson, R. J. (1999). Legal Infrastructure of High Technology Industrial Districts: Silicon Valley, Route 128, and Covenants Not to Compete, New York University Law Review, 74(3), 575-629.

Hall, B., Helmersy, C., Rogers, M., and V. Sena, (2013), The importance (or not) of patents to UK firms, Oxford Economic Papers, 65/3, 603-629. 
Hall, B., Helmers, C. Rogers, M., and V. Sena (2014), The Choice between Formal and Informal Intellectual Property: A Review, Journal of Economic Literature, 52(2): $375-423$.

Henning-Bodewig, F. (2006), Unfair Competition Law: European Union and Member States, Kluwer Law International, The Hague.

Henning-Bodewig, F. (2013), editor, International Handbook of Unfair Competition, C.H. Beck - Hart - Nomos.

Lemley, M. A. (2011). The Surprising Virtues of Treating Trade Secrets as IP Rights, in The Law and Theory of Trade Secrecy: A Handbook of Contemporary Research,

edited by R. Dreyfuss and K. Strandburg, Edward Elgar Publishing.

Lippoldt, D. and M. F. Schultz (2014), "Uncovering Trade Secrets - An Empirical Assessment of Economic Implications of Protection for Undisclosed Data", OECD Trade Policy Papers, No. 167, OECD Publishing

Executive Office of the President of the United States. (2013). Administration Strategy on Mitigating the Theft of US Trade Secrets, Washington.

Ohly, A. (2011). Free Access, including Freedom to Imitate, as a Legal Principle: a Forgotten Concept?, in The Structure of Intellectual Property Law: Can One Size Fit All?, A. Kur and V. Mizaras, eds., Edward Elgar Publishing.

Posner, R., Landes W. and D. Friedman (1991), Some Economics of Trade Secret Law, Journal of Economic Perspectives 5/61, 61-72.

Posner,R. (2007), Economic Analysis of Law, 7th edition, Aspen Casebooks.

Rønde, T. (2001). Trade secrets and information sharing. Journal of Economics $\& 3$ Management Strategy, 10(3), 391-417.

Saxenian, A. (1994). Regional advantage: Culture and competition in Silicon Valley and Route 128. Harvard University Press.

Singh, N., and Vives, X. (1984). Price and quantity competition in a differentiated duopoly. The RAND Journal of Economics, 15, 546-554. 


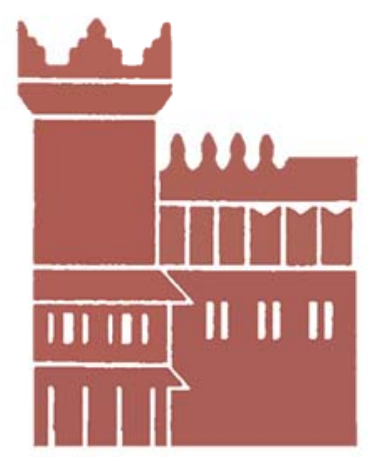

Alma Mater Studiorum - Università di Bologna DEPARTMENT OF ECONOMICS

Strada Maggiore 45

40125 Bologna - Italy

Tel. +39051 2092604

Fax +390512092664

http://www.dse.unibo.it 